Pikate Novels 


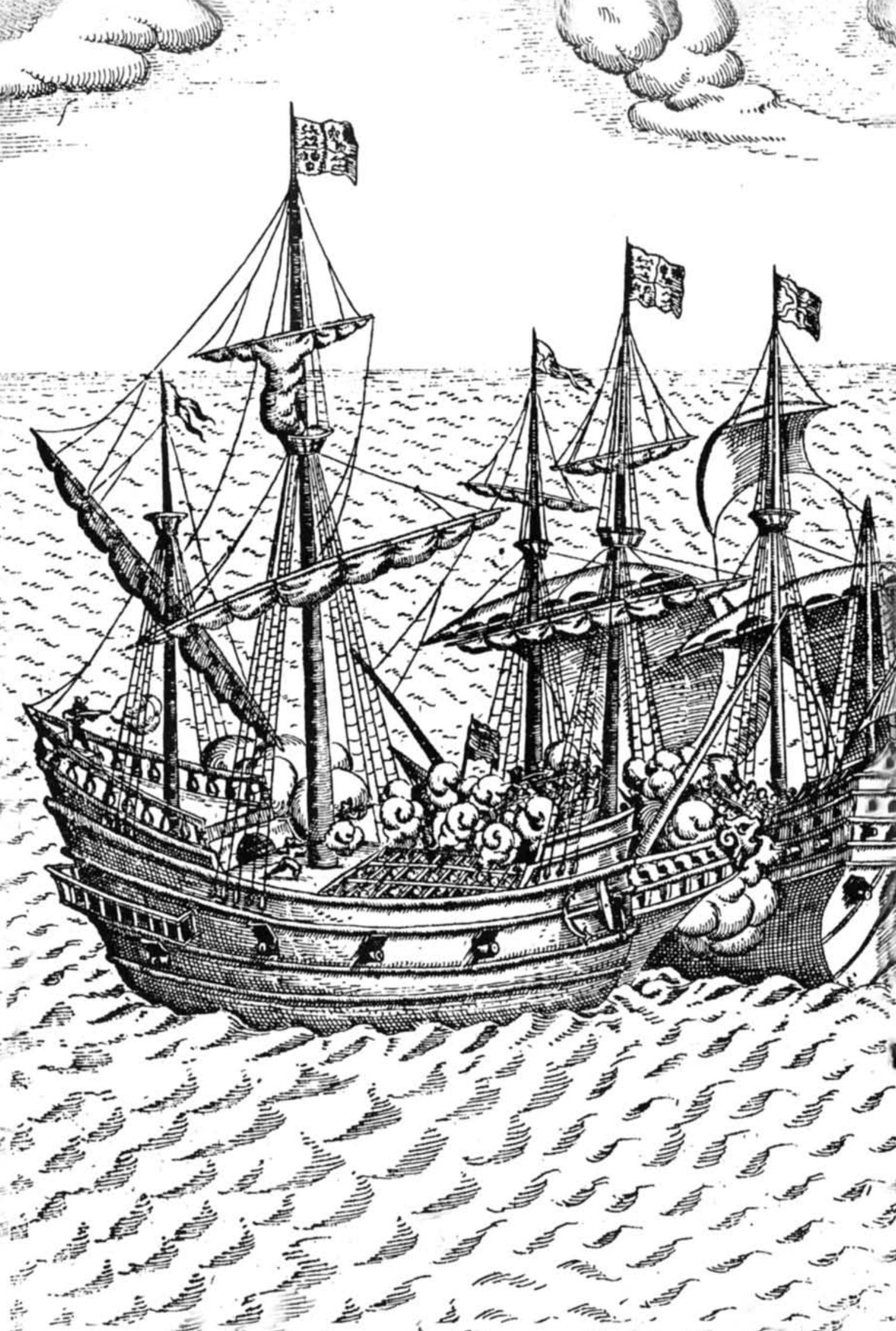




\section{Pikate Novels}

Fictions of Nation Building in Spanish America

Nina Gerassi-Navarro

Duke University Press Durham and London

1999 
(C) 1999 Duke University Press

All rights reserved

Printed in the United States of America

on acid-free paper @

Designed by C. H. Westmoreland

Typeset in Palatino with Oxford display

by Tseng Information Systems, Inc.

Library of Congress Cataloging-in-Publication

Data appear on the last printed page

of this book. 
